\title{
Lomber Ateşli Silah Yaralanması Sonucu Gelişen İzole Nörojenik Mesane
}

\author{
Isolated Neurogenic Bladder Caused by Lumbal Gunshot Injury

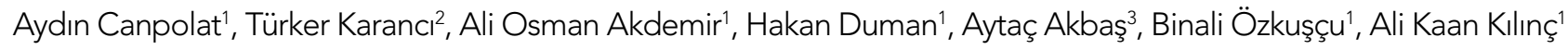 \\ ${ }^{1} T a k s i m$ Eğitim ve Araştırma Hastanesi, Nöroşirürji Kliniği, İstanbul, Türkiye \\ ${ }^{2}$ Özel Medicana Hastanesi, Nöroşirürji Kliniği, İstanbul, Türkiye \\ ${ }^{3}$ Çankırı Devlet Hastanesi, Nöroşirürji Kliniği, Çankırı, Türkiye
}

\section{ÖZET}

Spinal kord travması, sebep olduğu geçici veya kalıcı fonksiyon bozuklukları ile halen ciddi bir sağlık problemi olmaya devam etmektedir. Travma sonrası gelişen nörojenik mesane, renal yetmezlik ve enfeksiyon gibi mortalite ve morbiditeyi arttıran ciddi sonuçlara yol açabilir. Ateşli silahla spinal yaralanma yaralanma, trafik kazasından sonra ikinci sıklıkla nörojenik mesane tablosuna yol açan etkendir. Spinal travma geçiren ve spinal şok döneminde olan bir olgu mesane ve barsak fonksiyonları kontrolü açısından mutlaka değerlendirilmeli ve gerekli önlemler erkenden alınmalıdır. Bizim olgumuzda, lomber spinal ateşli yaralanma sonrası izole nörojenik mesane gelişimi, uygun tetkiklerle tespiti ve yönetimi tartışılmıştır. (JAREM 2013; 3: 41-3)

Anahtar Sözcükler: Ateşli silah yaralanması, nörojenik mesane, spinal travma

\section{ABSTRACT}

Spinal cord injury, leading to temporary or permanent dysfunction still remains a serious health problem. Neurogenic bladder which occurs after trauma may lead to serious consequences such as renal failure and infection, which increases morbidity and mortality. Spinal injury with a firearm can lead to the second most common neurogenic bladder after traffic accidents. Patients who had spinal trauma should be examined due to the condition which occurs in spinal shock and to check bladder and bowel control functions. As can be seen in our case, isolated neurogenic bladder after spinal cord injury caused by firearms, is discussed with proper identification and management of investigations. (JAREM 2013; 3: 41-3)

Key Words: Gunshot injury, neurogenic bladder, spinal trauma

\section{Gíiş̧}

Ateşli silahla yaralanmaya bağlı spinal kord hasarı sonucu gelişen izole nörojenik mesane nadir rastlanılan bir durumdur. Lomber $\mathrm{L}$ 4-5 seviyesine uyan düzeyde ateşli silah yaralanması sonrası görülen nörojenik mesane olgumuzu ve yönetimini literatür eşliğinde tartışarak paylaştık.

\section{OLGU SUNUMU}

Otuz yaşında bayan hasta ateşli silahla yaralanma sonucu acil cerrahi polikliniğine başvurdu. İlk müdahalesi yapıldı. Solunum ve hemodinamik parametreleri stabil olduğu anlaşıldıktan sonra yapılan ilk fizik ve nörolojik incelemesinde lomber bölge yan kadrandan bir adet ateşli silah giriş deliği tespit edildi. Nörolojik muayenesinde motor ve duyu defisiti saptanmadı. Direk grafi (Resim 1, 2) ve lomber BT (Resim 3) ile L4-5 düzeyinde kanal içi mermi çekirdeği görüldü. Hasta acil olarak ameliyata alındı. Operasyonda mermi çekirdeğinin sol L5 laminasını kırdığı görüldü. L4 ve L5 total laminektomi uygulandı. Duranın bu düzeyde bütünlüğünün bozulduğu görülerek vertikal insizyon ile açıldı ve mermi çıkarıldı. Nöral dokularda yaralanma görülmedi. Dura su geçirmez olarak dikildi ve doku yapıştırıcı kullanılarak kapatıldı. Postoperatif dönemde olgunun nörolojik muayenesinde idrar inkontinans dışında ek bir nörolojik bulgu tespit edilmedi. Yaralanmadan sonraki 10. ve 45. günlerde iki defa ürodinamik inceleme, pelvik bölge ultrasonografi ve biyokimyasal tetkikleri yapıldı. İdrar yolu enfeksiyonu tespit edildi. Medikal tedavi ile enfeksiyon kontrol altına

Sunulduğu Kongre: 22-26 Nisan 2011 tarihlerinde Antalya'da düzenlenen 25. Yazışma Adresi / Address for Correspondence: Dr. Aydın Canpolat, Taksim Eğitim ve Araştırma Hastanesi, Nöroşirürji Kliniği, İstanbul, Türkiye Tel.: +905323260980 E-posta: aydincanpolat@yahoo.com alındı. Ürodinamik inceleme detrusor arefleksisi olarak rapor edildi. Kontrol MRI incelemede operasyon bölgesinin temiz olduğu görüldü (Resim 4). Fizyoterapi uygulanan hastanın taburcu edildikten iki ay sonra inkontinansının tamamen düzeldiği gözlendi.

\section{TARTIŞMA}

Spinal kord travması sonrası görülen nörolojik miksiyon disfonksiyonu büyük bir sosyal ve medikal problemdir. Travmayı izleyen dönemde oluşan renal problemlere bağlı mortalite, gelişen tıbbi yöntemler sayesinde giderek azalırken, kötü mesane ve barsak fonksiyonuna bağlı morbidite hala ciddi bir problemdir (1). Mesane; parasempatik efferent sinir S2-S4 dermatomundan orijin alır, pelvik sinir olarak mesaneye gider ve detrusor kontraksiyonunu sağlar. Sempatik efferent sinirler T11-L2'den çıkar ve hipogastrik sinir olarak mesane ve üretraya gider. Beta adrenerjik reseptörler mesane gövdesinde bulunarak düz kas gevşemesini sağlarken, alfa adrenerjik reseptörler mesane boynu ve üretrada bulunarak düz kas kontraksiyonunu sağlar. Somatik efferentler S1-S4 segmentten orijin alır ve pudental sinir yolu ile eksternal üretral sfinkteri innerve eder $(1,2)$. Başlıca koordinasyon merkezi pontin mezensefalik retiküler formasyondur (3). İstemli miksiyon kontrolü medial frontal lob ve corpus callosum tarafından sağlanırken, suprapontine lezyonlarda miksiyon olur ama istemsizdir (4). Sıklıkla spinal kord travmalı olgularda pontine mezensefalik retiküler formasyondan kontrol edilen işeme fonksiyonu, eşlik eden kafa travması yok ise etkilenmez $(1,4)$. Spinal kord travması sıklıkla 

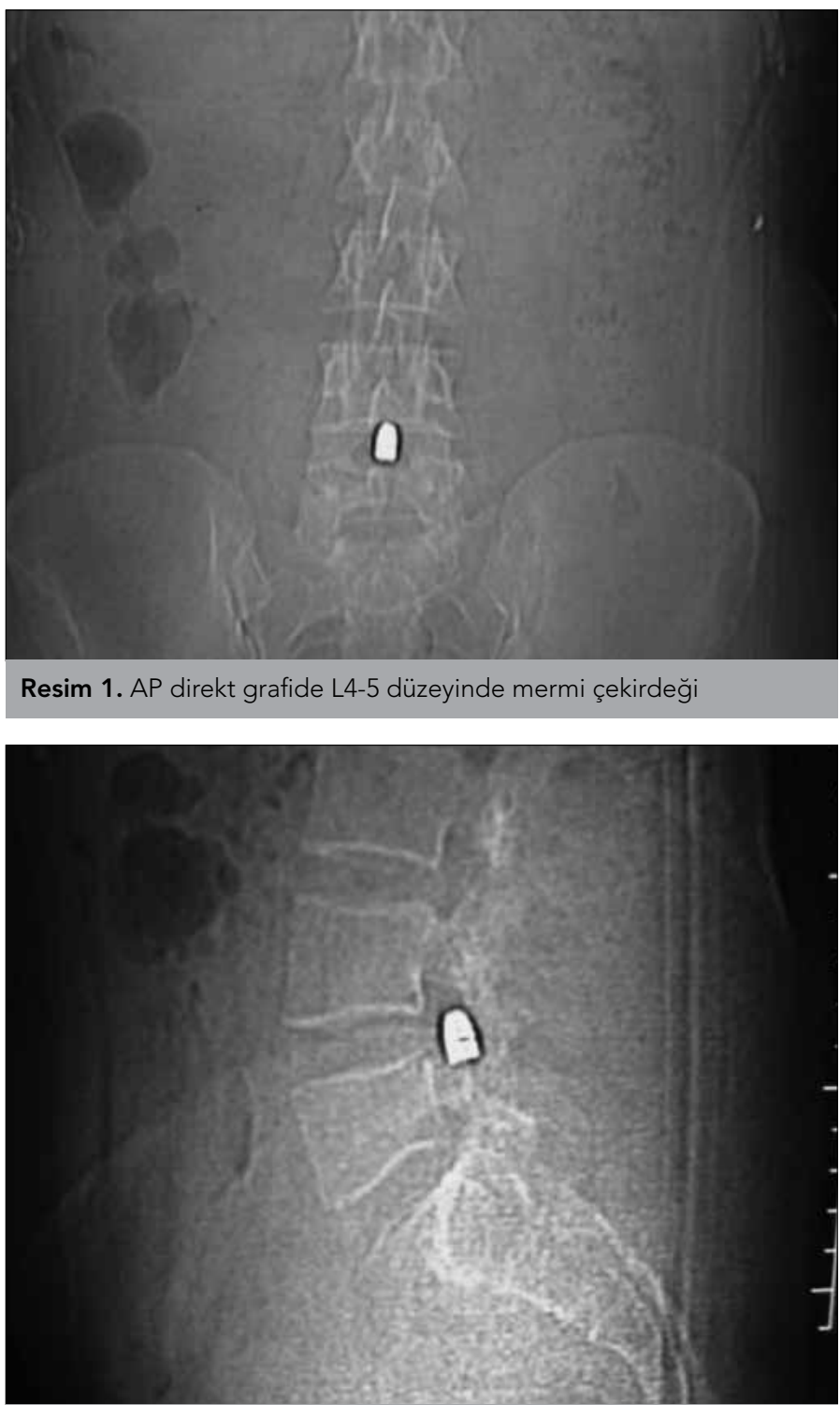

Resim 2. Lateral direkt grafide spinal kanal içinde mermi çekirdeği

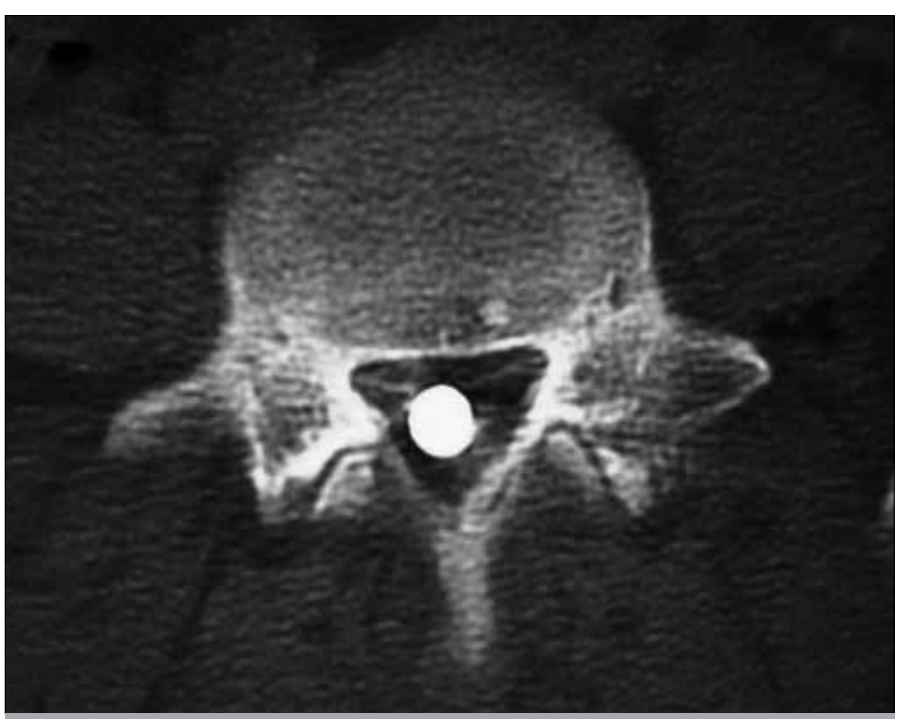

Resim 3. Bilgisayarlı tomografide spinal kanal içinde izlenen mermi çekirdeği

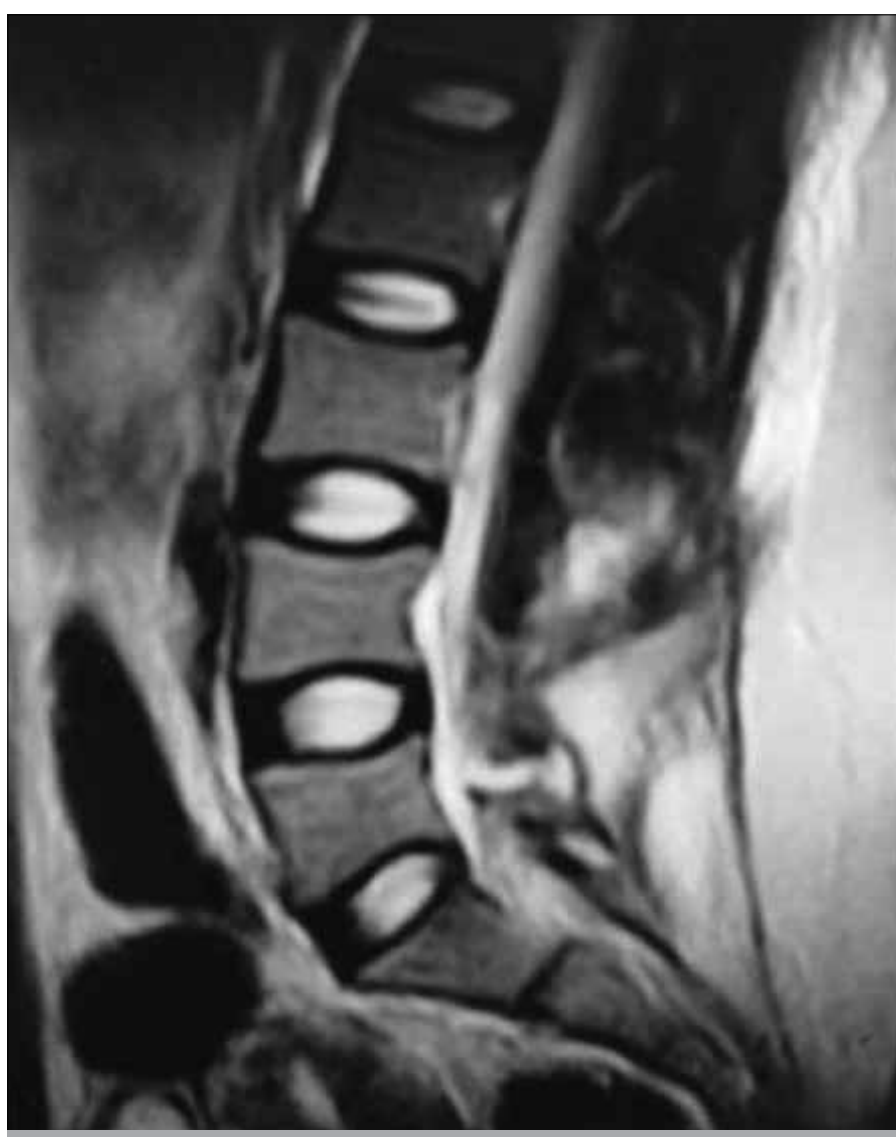

Resim 4. Ameliyat sonrası MR'da spinal kanal ve operasyon bölgesi izleniyor

mesane ve sfinkter disfonksiyonu ile birlikte görülür $(5,6)$. Spinal lezyonlar komplet ve inkomplet olabilir. Bunun sonucunda klinik ve nörolojik muayene tek başına nörolojik disfonksiyonu tayin etmede yeterli olmayabilir (7). Ürodinamik inceleme nörolojik durumu tayin etmede gereklidir. Mesanenin dolum ve miksiyon fazları çalışılır. ilave olarak detrusor kontraksiyonu sırasında detrusor basıncı ve kompliansı test edilir. Spinal şok travmadan sonra yaklaşık üç ayda çözülür ve detrusor aktivitesi kaydedilmeye başlar (8). Literatürde spinal kord hasarı yapan en sık nedenler sırası ile motorlu araç yaralanması, ateşli silahla yaralanma, düşme yer alır. Ateşli silahla yaralanma yüksek enerji kaynaklı bir travmadır. Merminin oluşturduğu kinetik enerjiye bağlı kavitasyon ve konküziv etkiyle doku hasarı oluşur (5). Dokuda direkt temas olmadan yanma ve iskemi ile de hasar oluşturabilir. Kaplan ve ark. (8) 489 olguluk bir çalışmada; değişik nedenlere bağlı spinal kord hasarı ile mesane, sfinkter fonksiyonu ve nörolojik defisit arasındaki ilişkiyi analiz etmişlerdir. Spinal kord hasarı sonrası başlıca üç tip ürodinamik patern tespit edilmiştir; bunlar 1. detrusor hiperrefleksisi ve sfinkter dissinerjisi (DESD), 2. detrusor hiperrefleksi ama sfinkter normal (DH), 3. detrusor arefleksi (DA). Genellikle lomber bölgede bir yaralanmada DA daha sık görülürken, torasik ve servikal bölgede DESD ve DH daha sıklıkla görülür (9). Bizim olgumuzda travma sonrası gelişen inkontinans görülmesi üzerine yapılan ürodinamik inceleme DA olarak rapor edildi. Inkontinans olarak ifade edilen idrar tutma fonksiyonunda yetersizlik nörojen mesanenin en sık karşılaşılan belirtilerindendir. İdrarı zorlanarak yapma (damla damla tarzında olacak kadar), idrar akımında azalma ya da idrarını yapamama gibi belirtiler de nörojenik mesanenin bulgu- 
ları olarak görülebilir. Özellikle retansiyon yavaş gelişirse, böbreklerde şişme ve böbrek fonksiyonlarında bozulma olabilirken bu tabloya üriner enfeksiyon eklenmesi durumu daha komplike hale getirebilir. Olgumuzda olduğu gibi spinal kord hasarı yapan ateşli silah yaralanmalarında merminin kanal içine girerek nöral dokular ile teması, genellikle tam veya tama yakın fonksiyon kaybına yol açabilmekle birlikte, kemikler ve diğer yumuşak dokular tarafından mermi çekirdeğinin enerjisinin absorbe edilmesi ile kayıp kısmi olabilir. Motor ve duyu defisiti olmaksızın sadece sfinkter fonksiyon bozukluğu oldukça seyrektir. Erken rehabilitasyon ve enfeksiyon kontrolü ile başarılı sonuç almak mümkündür.

\section{SONUÇ}

Spinal kord travması değişik nedenlere bağlı olarak gelişebilir. Yaralanma sonrasında görülen mesane ve sfinkter fonksiyon bozuklukları, spinal kord lezyon düzeyi ve travma tipi ile ilişkilidir. Ateşli silahla olan spinal kord travmasında bulgular genellikle ağırdır ve nörolojik fonksiyonlarda düzelme olasılığı zayıftır. Nörolojik muayeneyi takiben radyolojik görüntüleme ve ürodinamik testler önemli tanı metotlarıdır. Yaralanmanın şekli ve nörolojik tablonun ağırlığı ne olursa olsun, zamanında rehabilitasyon başlanması son derece önemlidir. Sfinkter bozukluğu olan olgularda enfeksiyon kontrolu ile prognoz daha iyi seyreder.

\section{Çıkar Çatışması / Conflict of Interest}

Yazarlar herhangi bir çıkar çatışması bildirmemişlerdir.

No conflict of interest was declared by the authors.

Hakem değerlendirmesi: Dış bağımsız.

Peer-review: Externally peer-reviewed.

\section{Yazar Katkıları / Author Contributions}

Fikir / Concept - T.K..; Tasarım / Design - A.C., A.O.A.; Denetleme / Supervision - A.O.A.; Kaynaklar / Funding - H.D., A.A.; Malzemeler / Materials - A.C.; Veri toplanması ve/veya işlemesi / Data Collection and/or Processing - B.Ö., A.K.K.; Analiz ve/veya yorum / Analysis and/ or Interpretation - A.C., A.O.A.; Literatür taraması / Literature Review - A.O.A., A.C.; Yazıyı yazan / Writer - A.C..; Eleştirel Inceleme / Critical Review - A.O.A..; Diğer / Other - H.D., A.A., B.Ö., A.K.K.

\section{KAYNAKLAR}

1. Samson G, Cardenas DD. Neurogenic bladder in spinal cord injury. Phys Med Rehabil Clin N Am 2007; 18: 255-74. [CrossRef]

2. Clinical practice guidelines: Neurogenic bowel management in adults with spinal cord injury. Spinal Cord Medicine Consortium. J Spinal Cord Med 1998; 21: 248-93.

3. Carlsson CA. The supraspinal control of the the urinary bladder. Acta Pharmacol Toxicol (Copenh) 1978; 43: 8-12. [CrossRef]

4. Benevento BT, Sipski ML. Neurogenic bladder,neurogenic bowel, and sexual dysfunction in people with spinal cord injury. Phys Ther 2002; 82: 601-12.

5. Sacomani CA, Trigo-Rocha FE, Gomes CM, Greve JA, Barros TE, Arap $\mathrm{S}$. Effect of the trauma mechanism on the bladder-sphincteric behavior after spinal cord injury. Spinal Cord 2003; 41: 12-5. [CrossRef]

6. Xiao CG. Reinnervation for neurogenic bladder: historic review and introduction of a somatic-autonomic reflex pathway procedure for patients with spinal cord injury or spina bifida. Eur Urol 2006; 49: 22-8. [CrossRef]

7. Wyandaele JJ. Correlation between clinical neurological data and urodynamic function in spinal cord injured patients. Spinal Cord 1997; 35: 213-6. [CrossRef]

8. Kaplan SA, Chancellor MB, Blaivas JG. Bladder and sphincter behavior in patients with spinal cord lesions. J Urol 1991; 146: 113-7.

9. Rudy DC, Awad SA, Downie JW. Eksternal sphincter dyssynergia: an abnormal continence reflex. J Urol 1988; 140: 105-10. 